\title{
Postulados del poder y la formación educativa en Colombia*
}

\author{
ALEJANDRO CASAS*
}

Recepción: 12 de enero de 2019

Aprobación: 03 de junio de 2019

Forma de citar este artículo: Casas, A. (2019). Postulados del poder y la formación educativa en Colombia. Cuadernos de Lingüística Hispánica, (34), pp 133-154.

두 $10.19053 / 0121053 X . n 34.2019 .9380$

* Artículo de investigación producto de investigación del Proyecto SGI 1735, inscrito en la Dirección de Investigaciones de la Universidad Pedagógica y Tecnológica de Colombia

** Magíster en Lingüística, Universidad Pedagógica y Tecnológica de Colombia. Candidato a doctor en Lenguaje y Cultura de la misma Universidad. Correo electrónico brisadelcielo39@yahoo.es. (iD https://orcid.org/0000-0003-2927-3777 


\section{Resumen}

Este artículo tiene como objetivo analizar la relación entre los postulados de poder y la educación colombiana; en particular, la correspondencia entre formación laboral y la reproducción del orden ideológico estatuido. El tipo de investigación es el análisis crítico del discurso, mediante un método dialógico entre las teorías del poder de Foucault (1988, 2002) y de Althusser $(1969,1971,1988)$. Las oposiciones de estas dos teorías acerca del poder surgen porque se han pensado dentro de marcos institucionales, tales como las escuelas (Foucault, 2002) y la ineludible relación con las ideologías y políticas estatales (Althusser, 1988). Se muestran las disparidades y confrontaciones entre estas dos teorías sobre poder. La conclusión muestra las relaciones de poder entre el Estado colombiano y los escenarios escolares públicos, así como la forma en que funcionan los dispositivos de poder en estos escenarios (Jäger, 2003), siempre desde la posibilidad de la emancipación humana para transformar su entorno.

Palabras clave: ideología, poder político, cultura dominante, participación social.

\section{Postulates of the Power and Educational Training in Colombia}

\section{Abstract}

This paper analyzes the relationship between the postulates of the power and Colombian education, particularly the correspondence between labor training and the reproduction of the established ideological order. The type of research is the critical analyzes of the discourse, through a dialogical method among power theories

of Foucault $(1988,2002)$ and Althusser $(1969,1971,1988)$. Oppositions of these two theories about power arise because they have been thought within the institutional frameworks, such as schools (Foucault, 2002) and the unavoidable relationship with political ideologies and policies (Althusser, 1988). Disparities and confrontations among these two theories on power are shown. The conclusion shows the power relations between the Colombian State and the public school scenarios, as well as the way in which power devices work in these scenarios (Jäger, 2003), always from the possibility of human emancipation to transform its environment.

Keywords: ideology, politics power, dominant culture, social participation. 


\section{Postulats du pouvoir et la formation éducative en Colombie}

\section{Résumé}

Cet article a comme objectif le fait d'analyser le rapport entre les postulats de pouvoir et l'éducation colombienne, en particulier, la correspondance entre formation professionnelle et la reproduction de l'ordre idéologique statué. Le type de recherche est l'analyse critique du discours, à travers une méthode dialogique entre les théories du pouvoir de Foucault $(1988,2002)$ et d'Althusser $(1969,1971,1988)$. Les oppositions de ces deux théories sur la pouvoir surgissent parce qu'elles ont été pensées dans des cadres institutionnels, tels que les écoles (Foucault, 2002) et l'inéluctable rapport avec les idéologies et les politique d'état (Althusser, 1988). On montre les disparités et les confrontations entre ces deux théories sur le pouvoir. La conclusion montre les rapports de pouvoir entre l'État colombien et les scénarios scolaires publics, ainsi que la manière de fonctionnement des dispositifs de pouvoir là-dedans (Jäger, 2003), toujours dès la possibilité d'émancipation humaine pour transformer son entourage.

Mots clés: idéologie, pouvoir politique, culture dominante, participation sociale.

\section{Postulados do poder e formação educacional na Colômbia}

\section{Resumo}

Este artigo tem como objetivo analisar a relação entre os postulados do poder e a educação colombiana; em particular, a correspondência entre a formação profissional e a reprodução da ordem ideológica estatutária. 0 tipo de investigação é a análise crítica do discurso, por meio de um método dialógico entre as teorias do poder de Foucault (1988, $2002)$ e de Althusser $(1969,1971,1988)$. As oposições dessas duas teorias sobre o poder surgem porque elas foram pensadas em estruturas institucionais, como as escolas (Foucault, 2002) e a inevitável relação com ideologias e políticas estatais (Althusser, 1988). As disparidades e confrontos entre essas duas teorias do poder são mostradas. A conclusão mostra as relações de poder entre o Estado colombiano e os cenários das escolas públicas, bem como a maneira como os dispositivos de poder funcionam nesses cenários (Jäger, 2003), sempre a partir da possibilidade da emancipação humana de transformar seu ambiente.

Palavras-chave: ideologia, poder político, cultura dominante, participação social 


\section{Introducción}

La investigación hace parte de la construcción teórica de la tesis doctoral denominada "Dispositivos de poder en el 'Plan Nacional de Lectura y Escritura de Educación inicial, básica y media de 2011'", adscrita al Doctorado en Lenguaje y Cultura de la Universidad Pedagógica y Tecnológica de Colombia, dentro de la línea de investigación "Lenguaje, Sociedad y Cultura". La temática de esta disertación tiene que ver con las nociones de poder, los postulados del poder y la articulación dispositiva del poder en el escenario de la educación en Colombia, cuyas teorías de base son la teoría de la reproducción social y la ideología del poder de Althusser $(1969,1971,1988)$ y la teoría del poder disciplinario de Foucault $(1988,2002 \mathrm{a})$.

En la situación problemática se observa con atención la dispersión semántica, teórica y epistemológica de las nociones de poder, para entablar discursos coherentes con las prácticas cotidianas de diversos escenarios sociales, en este caso, el de la educación en Colombia. Las teorías de la reproducción social y de la ideología del poder en Althusser han servido como faro teórico para desarrollar ejercicios investigativos que se aproximan a la temática de este texto.

"Dos extraños compañeros de cama. La ideología y el poder en Althusser y Foucault", de Pablo Francisco Pérez Navarro (2007), publicado por la revista Tabula Rasa de la Universidad Javeriana, muestra la importancia crucial de preservar en la teoría crítica una cierta noción de ideología, especialmente tal como fue desarrollada por Althusser y complementada posteriormente por la teoría del poder foucaultiana (Pérez, 2007). En este caso, la orientación disciplinar está enfocada en torno de las nociones de sujeto, verdad, identidad y trabajo. Por otra parte, aunque en el ámbito internacional abundan los trabajos sobre el poder y sus distintas relaciones, el enfoque que se plantea implica mostrar las relaciones que se dan entre los dispositivos de poder y la formación en los escenarios escolares colombianos. En Colombia, este enfoque no ha sido trabajado con amplitud y en este caso merece un análisis y una reflexión que puedan dar luces en documentos futuros de investigación.

Como objetivo del texto se plantea analizar la relación entre los postulados de poder y algunos aspectos de la educación colombiana, así como desarrollar un diálogo teórico entre la teoría de la reproducción social y la ideología del poder de Althusser $(1969,1971,1988)$ y la teoría del poder disciplinario de Foucault $(1988,2002 b)$.

En primer lugar, se presenta un marco teórico sobre la noción de poder: dispositivos de poder, mecanismos y modalidades; en segundo lugar, se provee una metodología 
de carácter dialógico, denominada "Los postulados del poder: un diálogo teórico entre Foucault y Althusser", en la que se confrontan los postulados del poder desde los dos autores mencionados; en tercer lugar, se ofrecen unos resultados de investigación, dentro del ámbito educativo colombiano, con respecto al precedente diálogo teórico, denominado "Relación entre los postulados del poder y la educación colombiana". Al final se proponen unas conclusiones que dan razón de un panorama que siempre tiene en cuenta las posibilidades de la acción y la participación humana en los procesos de emancipación.

\section{La noción de poder: dispositivos de poder, mecanismos y modalidades}

En este acápite se desarrolla la noción de poder desde la comprensión de los dispositivos de poder, los mecanismos de que se vale el poder para su ejercicio y las modalidades en que el poder se vislumbra y se ejerce en diferentes esferas de la sociedad, con base en los postulados de autores como Siegfried Jäger (2003), Michael Foucault (1988, 2002a, 2002b) y Louis Althusser $(1969,1971,1988)$, entre otros.

La noción de poder tiene un recorrido conceptual bastante largo en el campo teórico $^{1}$. La experiencia social más rudimentaria nos confirma que formar parte de un grupo cualquiera implica la sumisión a un poder. Tal es, en su generalidad, el hecho social del poder (Lapierre, 1959). En ese sentido, el poder impregna las relaciones humanas en todos los ámbitos de la sociedad y, en consecuencia, tiene diversas formas de manifestación, tales como la obediencia y la convicción. En el caso de la obediencia, se trata del ingreso de los individuos a ciertos círculos sociales, en los que no intermedia el convencimiento propio del sujeto. La situación de las escuelas es un claro ejemplo de ello, puesto que los escolares no ingresan por motivos de autoafirmación de su autonomía, sino más bien mediados por la acción de sus familiares. En el caso de la convicción operan modalidades de poder ${ }^{2}$, como la persuasión; esto es, el individuo se afirma autónomamente a los códigos, conductas y comportamientos de cada grupo, con base en la operatividad del lenguaje y de los modos de presión en que se transforman 0 validan importantes opiniones para su identidad.

1 Históricamente, el papel del poder abarca todas las civilizaciones, todas las culturas y todos los grupos sociales. Tratados como El Capital, de Karl Marx, Vigilar y castigar, de Foucault, Ideología y los aparatos ideológicos de Estado, de Louis Althusser, han revisado con minuciosidad los elementos distintivos del poder en las sociedades, ya sea desde una síntesis económica, institucional o del Estado. Aunque son algunos de los autores que aquí se refieren, no son los únicos que han abordado el problema del poder como concepto, pero han servido como punto de partida para las conexiones conceptuales que se quieren establecer en este trabajo.

2 Las modalidades de poder de la "sutileza" operan mediante la motivación, la insistencia y la sugestión constante. Más adelante se explicitan con mayor profundidad estas modalidades. 
El hecho de pertenecer a un grupo es reconocer, en efecto, que este puede exigirnos ciertos actos, una conducta de acuerdo con los fines que puede fijarse a nuestros deseos, ciertos límites y prescribir a nuestras actividades ciertas formas de conducta (Lapierre, 1959). En ese sentido, cada individuo está dispuesto a admitir estos requerimientos: cumplir, respetar estos límites y las formalidades, bajo el escarmiento de perder el vínculo social que los une al grupo. Lapierre (1959) afirma que tal es el poder del grupo y, correlativamente, el deber de sus miembros.

En la conformación de grupos sociales se vislumbran una organización y una distribución de roles. Uno de los primeros roles consiste en las relaciones de poder que se cimientan sobre una operatividad brutal o simbólica, en otras palabras, como fuerzas que se legitiman y se ejercen sobre el otro, de manera violenta o semiótica. Foucault (2002a) define la operatividad del poder en términos de ejercicio y posesión; es decir, la trama del poder no es una pertenencia como tal de alguien, sino más bien está establecido desde una estrategia de ejecución.

Hay que admitir en suma que este poder se ejerce más que se posee, que no es el "privilegio" adquirido o conservado de la clase dominante, sino el efecto de conjunto de sus posiciones estratégicas, efecto que se manifiesta y a veces acompaña la posición de aquellos que son dominados. (Foucault, 2002a, p. 33)

Un ejemplo de las estrategias de ejecución puede darse en torno de la normativa. Las normas tienen un margen de cumplimiento y un margen de transgresión. Allí siempre estará la decisión propia, la autonomía y la libre elección de transgredir o de cumplir las normas. La estrategia sería la condicionalidad, de modo que habrá penas si se trasgreden, o la tranquilidad del individuo, en caso de que se cumpla la normativa. Por consiguiente, la relación entre posesión del poder y ejercicio del poder estriba principalmente en la posibilidad de entenderla como una dinámica. El poder no existe en términos de alguien que lo ejerce, en otras palabras, existe en la diversidad de formas en que se ejerce sobre los individuos, los dominados, los sujetos en condición de sumisión. Por consiguiente, hay un funcionalismo por extensión del poder. El poder nunca se posee, el poder se ejerce (Deleuze, 2014).

Para que se pueda entrever la dimensión del poder, devenida de la perspectiva precedente, se debe comprender la noción de dispositivos de poder, como base de lo que puede considerarse la dinámica del poder. En realidad, los dispositivos de poder pueden concebirse como un "conjunto de obras de arte" que, al encontrarse ensambladas y entretejidas unas con otras de diversas maneras, constituyen un dispositivo societal global (Jäger, 2003). Esto es, como conjunto de obras de arte requieren comprensión, 
elucidación y visibilización, a partir de la concepción de un sentido individual y colectivo que generalmente está profundamente velado. Por ejemplo, La Gioconda de Leonardo Davinci tiene elementos estéticos, entrelazamiento de planos, técnicas visuales y modos de interpretación textual. Uno de ellos tiene que ver con la técnica: el logro del artista es un retrato de una ambigüedad calculada en el semblante y un esfumado (sfumato) muy fino, técnicamente conseguido por la superposición de cerca de veinte capas pictóricas de una delgadez extrema (Gilabert, 2012). Por eso, la noción de discursos invisibles toma relevancia en la medida en que el dispositivo se comprenda como una entidad oculta y pueda ser develada, como se mostró en el ejemplo anterior.

Como ensamblajes y tejidos, los dispositivos de poder suponen una red de significados que no solo están presentes en el lenguaje, sino también en las prácticas sociales. Jäger reinventa el concepto de "dispositivo" de Foucault, concibiéndolo como un caparazón que engloba tanto las prácticas y las materializaciones discursivas como las no discursivas 3 (Meyer, 2003). Para hallar la relación existente entre poder y los dispositivos de poder es fundamental la reflexión sobre la noción de conocimiento en términos de validez; solo puede ser comprendido en un determinado lugar y en un determinado momento, es decir, en un contexto establecido. Asimismo, la relevancia del mismo está anclada en su evolución, en las formas en que es trasmitido, en la función que tiene para constituir a los sujetos y configurar la sociedad, así como el impacto que tiene en el desarrollo general de las comunidades (Jäger, 2003).

En esa perspectiva, por conocimiento se entiende todos los tipos de contenidos que dan forma a la conciencia o todos los tipos de significados utilizados por diferentes personas históricas, con el fin de interpretar y moldear la realidad circundante (Jäger, 2003). En otras palabras, el conocimiento visto desde este enfoque no pasa inadvertido frente a su relación con el poder y la ideología. No obstante, las relaciones de poder solo pueden ejercerse a través de la relación existente entre sociedad y conocimiento. Las relaciones de poder tienen alcances que se dimensionan por medio del lenguaje insertado en una determinada cultura. El poder exige una relación consigo mismo: deviene acciones, roles y contextos; el escenario del poder comprende unos actores que se interrelacionan a partir de determinados roles: ejecutores del poder y sujetos en condición

3 Para Jäger (2003), el discurso en Foucault está excesivamente atrapado en lo verbal. Esto es, las prácticas y materializaciones discursivas, en Foucault, se entienden como todo tipo de verbalización; por otra parte, las prácticas y materializaciones no discursivas serían las actividades, acciones y manifestaciones. Por eso, Jäger (2003) inserta los postulados de Leontwjev y engloba tales prácticas y materializaciones, entendiéndolas como el dispositivo. 
de dominación; es decir, las acciones, los roles y los contextos se constituyen como el ejercicio del poder en medio de relaciones humanas.

El poder está definido por puntos innumerables de enfrentamiento, focos de inestabilidad, cada uno de los cuales comporta sus riesgos de conflicto, de luchas y de inversión, por lo menos transitoria, de las relaciones de fuerzas (Foucault, 2002a). Esto implica que el poder no es la estructura de una política, de una ley o de una norma, su revisión o las condiciones textuales en que puede observarse, sino un entramado que se practica en medio de condiciones de lucha y desequilibrio, es decir, en medio de un discurso.

El efecto y la condición natural del poder consisten en atravesar las esferas de una sociedad, en influir en aquellos que viven la sumisión y el control. Por eso el autor francés afirma que la aplicación del poder los invade, pasa por ellos y a través de ellos; se apoya sobre ellos, del mismo modo que ellos mismos, en su lucha contra él, se apoyan a su vez en las presas que ejercen sobre ellos (Foucault, 2002a). La teoría foucaultiana permite explicar la existencia de un ámbito totalizador del poder, en el que se encuentran diversas formas estratégicas de su ejercicio, como se ha venido ejemplificando. En otras palabras, se puede decir que:

[...] Estas relaciones descienden hondamente en el espesor de la sociedad, no se localizan en las relaciones del Estado con los ciudadanos o en la frontera de las clases y no se limitan a reproducir al nivel de los individuos, de los cuerpos, unos gestos y unos comportamientos, la forma general de la ley o del gobierno; si bien existe continuidad, no existe analogía ni homología, sino especificidad de mecanismo y de modalidad. (Foucault, 2002a, p. 34)

No basta una coordinación o una sumisión de los cuerpos, la orden y su cumplimiento, sino que el mecanismo y la modalidad entraña una misión a la profundidad de los seres, es decir, a la manera de Marx y Engels (2000), una búsqueda incesante de la enajenación de los sujetos. En ese orden de ideas, los individuos ceden a una concepción de humanidad, inmersa en relaciones que constituyen el ejercicio, la acción y la concreción del poder.

Por tanto, se puede entender el mecanismo de poder como una acción iterativa de quien ejerce el poder sobre quien está en condición de sumisión, una intensión ${ }^{4}$ masificada, extendida en el tiempo necesario hasta producir el efecto de la aceptación y la resignación. Por otra parte, la modalidad se refiere a la diversidad de prácticas que se

4 En este texto, esta intensión se refiere a una fuerza en las diferentes estructuras sociales. 
pueden efectuar para lograr tal sumisión; entre ellas están las ejercidas por los medios de comunicación, la normativa, las creencias religiosas, algunas instituciones disciplinares, como la iglesia y la escuela, y en general, la producción y reproducción de un lenguaje que opera con dirección hacia la desigualdad social. De modo que, si se observa con atención, el poder actúa desde varios postulados, de determinadas maneras y en diferentes instituciones. Estos postulados se fundamentan desde una perspectiva social que incluye una mirada operativa del poder (Foucault, 1988, 2002a, 2002b; Althusser, 1969, 1971, 1988). Deleuze, en su texto El poder: curso sobre Foucault II (2014), explica estos principios como base para la comprensión del poder, sobre todo en un marco institucionalizado, en el que toma relevancia la oposición y la complementariedad entre la teoría de la reproducción social de Althusser $(1969,1971,1988)$ y la del ejercicio del poder de Foucault (1988, 2002a, 2002b).

\section{Los postulados del poder: un diálogo teórico entre Foucault y Althusser}

Este acápite desarrolla un diálogo teórico clave en la comprensión de las relaciones de poder, desde los autores ya mencionados. Otros como Giroux (2014) y Deleuze (2014), entre otros, participan activamente en esta metodología dialógica, con el propósito de alimentarla y recrearla desde variadas perspectivas, con el propósito de comprender las implicaciones sociales de los postulados del poder en una sociedad como la colombiana.

El primer postulado se centra en la idea de poder como propiedad, devenido de las teorías clásicas del poder del marxismo. En modo alguno, esta perspectiva puede asumirse como totalitaria; más bien, se refiere a la estrategia como funcionamiento de un campo social o de una sociedad. Esto denota que una sociedad es estratégica; la consecuencia es nuclear: el poder no es una propiedad de nadie; por el contrario, es el ejercicio de todo el mundo. Eso es lo que quiere decir poder, hay un principio estratégico — primer principio- (Deleuze, 2014).

En ese sentido, es significativo recalcar que en determinados momentos los sujetos participan de una tensión constante en la relación de fuerzas. Esto es, los sujetos se aproximan al poder y lo ejercen de vez en cuando, pero no significa que esta dinámica sea equitativa en la distribución del mismo. Por consiguiente, hay una inclinación estratégica que muestra escenarios del poder situados en un juego de relevos y que se dan en un ejercicio continuo y dinámico por diferentes individuos, instituciones y grupos sociales. 
El segundo postulado tiene que ver con la localización: hay una tendencia a localizar el poder en un aparato (Deleuze, 2014). En este postulado es preciso observar dos versiones antitéticas. En las áreas del régimen privado solo hay una dispersión aparente del poder, pero funciona como un aparato del Estado 5 (AE) de carácter especial (Althusser, 1988). Por lo contrario, en la teoría foucaultiana, este supone relaciones de poder, pero no las explica por medio de una localización ${ }^{6}$ (Deleuze, 2014).

En esa medida, la conclusión estaría dada por el siguiente razonamiento: tanto en el espacio privado como en el público, el AE no es donde se ubica el poder, sino emerge para organizar ese poder. Es decir, los poderes públicos se originan en sí mismos, proceden, pero el Estado los controla y los cubre, incluso también, a los regímenes privados. En otras palabras, el aparato del Estado no hace más que gestionar procedimientos de poder que vienen de otra parte (Deleuze, 2014). Pero, además, hay algo característico en la denuncia a este postulado: el AE se tiende sobre un régimen de disciplinas. De modo que las disciplinas de la escuela, del ejército, las disciplinas privadas, las de la iglesia, siempre han precedido al Estado, pero las técnicas disciplinarias son recuperadas por el Estado, aunque no tengan su origen en el mismo (Deleuze, 2014); es allí, en la práctica, donde el Estado opera sus ejercicios de dominación y de poder desde lo local.

En otras palabras, no hay contradicción entre las siguientes ideas: el poder no se deja localizar y el poder consiste en focos locales (Foucault, 2002a). Esto significa que el poder se disemina, es difuso, se dispersa por todo el campo social (Deleuze, 2014). En relación con este postulado, es importante concluir que es en los espacios institucionales donde se practica el ejercicio del poder. Es en esos focos locales donde el poder se ejerce siempre bajo el velo o el cubrimiento del Estado, como lo denomina Deleuze (2014).

El tercer postulado que la teoría foucaultiana impugna es el de la subordinación. Es el postulado según el cual el poder estaría subordinado a un modo de producción como infraestructura (Deleuze, 2014). Esto es, el poder no depende de un sistema económico de producción, como lo presuponen Marx y Engels (2000) y, con posterioridad, Althusser (1988). El poder se relaciona con el sustrato económico, pero también está

5 Los aparatos del Estado son instrumentos ideológicos que permean y reproducen la sociedad a partir de sus discursos. Estos pueden ser, según Althusser (1971), el sistema de iglesias, el ámbito familiar, las relaciones de trabajo, el espacio jurídico, la política, los medios de comunicación, la escuela, entre otros. En la teoría de Foucault (1988, 2002a, 2002b) y los aportes de Deleuze (2014), se reconoce la misma concepción de aparato ideológico de Estado; sin embargo, ambos autores implican que el poder no se localiza en estos, sino más bien, que el aparato ideológico de Estado organiza el poder en las diferentes esferas de la sociedad.

6 Es importante comprender que localización -como postulado- no es igual a ubicación o a sitio; más bien, lo que señala la teoría foucaultiana tiene que ver con los focos locales. 
en otras esferas sociales, como se ha venido mostrando. La economía reconoce diversas relaciones de poder inherentes a los cuerpos y las almas, actuando dentro de estos; además, estas relaciones se sumergen en el interior del campo económico sobre las fuerzas productivas y las relaciones de producción (Foucault, 2002a).

"Las relaciones de poder [...] no están en posición de exterioridad respecto a otros tipos de relaciones [...] No están en posición de superestructura [...] Están presentes allí donde desempeñan un papel directamente productor" (Foucault, 2002a). En consecuencia, el poder es una estructura que contiene unos mecanismos inherentes a la economía; sin embargo, no son todos de los que dispone, pues esta también tiene mecanismos psicológicos, sociales, de aislamiento de grupos, mecanismos que operan sobre los medios de comunicación y las instituciones, entre otros. Por tanto, el poder y la producción económica no tienen una relación jerárquica, no pertenecen al orden "superestructura económica-ejercicio del poder sobre los dominados". Evidentemente, las relaciones de poder no derivan de las relaciones de producción, porque no hay relaciones de producción definibles independientemente del entrelazamiento que tienen con las relaciones de poder (Deleuze, 2014).

La objeción de Foucault es substancial, porque provee de elementos para discernir que el poder está en constante movimiento y no puede ser explicado solo desde la acumulación de capital y la reproducción social, a manera de calco o fotocopia perpetua de la sociedad. El hecho de pensar en una reproducción fiel de la sociedad simbolizaría la castración total de cualquier intento de subversión, emancipación, sublevación y comprensión propia de la situación contextual del oprimido.

Mientras Althusser (1988) tiene en cuenta tres características inherentes al poder —la instrucción de valores que mantienen las características de la producción de trabajo y capital; el uso de la fuerza (violencia) y la ideología (entendida, en este caso, como una psicología de las ideas, que se inserta sutilmente en los individuos a través del inconsciente) para sostener a las clases dominantes en las esferas de control7; ; la construcción de conocimiento y destrezas pertinentes, relevantes y conductuales para el trabajo-, Foucault piensa que el poder no es unilateral y exclusivo para esas esferas de control, y que tales características, si bien se soportan sobre una base económica, no comprenden en complejidad otras esferas de la sociedad que se dan en medio del discurso social.

7 Referente a esta categoría, se hará un análisis más profundo cuando se plantee la denuncia al quinto postulado, el que concierne a la modalidad. 
Es decir, si se comprende el principio de relevos que se da entre dominados y dominantes, es claro que el poder no pertenece a una élite ni se apoya en una doctrina unilateral de sus procedimientos, sino más bien, está difuminado entre los individuos. De modo que los sujetos que pertenecen a las clases sociales desfavorecidas tienen la posibilidad de ejercer procedimientos de liberación, emancipación y llevar a cabo desde sus propias luchas nuevas condiciones favorables a su situación. También, esto prefigura la postura de multiplicidad en Foucault (2002a), pues permite entrever que el poder dimensiona focos de inestabilidad que posibilitan a los individuos, en condición de opresión, construir espacios de autonomía y libertad.

El cuarto postulado tiene que ver con la esencia y el atributo. En cuanto a esto, Foucault (2002b) no lo determina como una clasificación de sometimiento entre dominantes y dominados. Por tanto, el poder no tiene esencia, sino que es funcional operatorio (Deleuze, 2014). El poder no tendría el atributo de una estructura rígida o de un orden jerárquico, sino por lo contrario, sería una relación. En esa medida, la relación de poder es el conjunto de las relaciones de fuerzas en un campo social, y desde entonces el poder pasa tanto por las fuerzas dominadas como por las dominantes (Deleuze, 2014). Como no tiene esencia, el poder no es un atributo que discierne entre lo dominante y lo dominado, sino más bien vincula esos dos conceptos bidireccionalmente, en medio de las tensiones propias de la relación de fuerza.

El quinto postulado a que se refiere Foucault (2002a) es concerniente a la modalidad. Según esta perspectiva, las teorías clásicas del poder se basan en dos modalidades: 0 bien procede de la violencia (la represión), o bien procede a través de la ideología. Represivo 0 ideológico, represión o ideología (Deleuze, 2014). Se puede afirmar que Foucault muestra que estas modalidades no son un recurso modal para practicar el dominio sobre los dominados.

Uno siente bien que es una alternativa muy pobre, porque lo que Foucault no cesa de mostrar es que el poder puede actuar sobre los cuerpos y sobre las almas, pero incluso cuando actúa sobre el cuerpo lo hace de un modo distinto al de la ideología, e incluso cuando actúa sobre el cuerpo lo hace de un modo distinto al de la violencia y la represión. (Deleuze, 2014, p. 48)

Lo que se acaba de afirmar tiene que ver con los procedimientos del poder. Para Deleuze (2014), esto viene a ser determinante, puesto que el poder tiene medios más sutiles para realizar sus procedimientos. En este sentido, no serán únicamente la represión y la ideología las que generen el ejercicio del poder. Es represivo en última instancia, sí, cuando no puede operar de otro modo, pero de lo contrario se las arregla muy bien 
sin ser represivo (Deleuze, 2014). Con base en lo anterior, el poder tiene modalidades graduales para desarrollar sus procedimientos. Principalmente, serían las modalidades de la sutileza las que tienen un amplio margen de práctica en el ejercicio del poder.

En consecuencia, se puede decir que Althusser $(1969,1971,1988)$ mantiene una perspectiva de oposición frente a las nociones de dominación y de poder: oposición entre clases de élite y subordinadas, oposición entre localización del poder en el AE y dominio en la vida cotidiana de los individuos, oposición entre superestructura e infraestructura ${ }^{8}$, oposición entre dominantes y dominados, oposición entre violencia y subyugación. Esta oposición plantea casi siempre una disposición macrofísica de acción-reacción; en ese sentido, esta teoría clásica del poder se basa en que las grandes entidades se organizan según oposiciones molares (Deleuze, 2014).

Por una parte, esta interacción se puede observar en dos niveles concretos. En un nivel superior, la ideología está pensada desde el espacio, el tiempo, las rutinas y rituales, específicamente, desde su funcionamiento en un ámbito institucional; la ideología, desde esa mirada, está centrada en la concepción del capital y de las clases dominantes, para apropiarse y hacer uso de los aparatos del Estado, fundamentales para reproducir la misma ideología y sostener la relación unidimensional entre sujetos dominantes y dominados.

Por otra parte, en un nivel inferior, las nociones de dominación y poder, en la concepción de Althusser $(1969,1971,1988)$, tienen el problema de comprender a los sujetos dominados, como entes que se dejan estructurar inconscientemente, para reproducir el sistema y la ideología de los sujetos dominantes. Allí, por lo menos, se infiere que existe una relación concluyente entre la psicología y el ejercicio ideológico de la dominación. En ambos niveles, estas nociones prescinden de la acción humana como una posibilidad para desarrollar procesos de emancipación; asimismo, el problema de la mente humana atravesada por construcciones ideológicas de carácter conductista, es demasiado ingenuo como para totalizar determinísticamente a los sujetos dominados en una eterna condición de sumisión.

Según lo anterior, Althusser $(1968,1971)$ propone que, a través de la ideología, la violencia y la represión, los procedimientos del poder se dan desde un margen bastante

8 La infraestructura, en la teoría de Marx y Engels, está determinada por la estructura social, el desarrollo y el cambio social, así como las fuerzas productivas y las relaciones de producción. La superestructura depende de la primera. Se incluyen las relaciones jurídicas, las formas políticas, artísticas, religiosas, educativas de un contexto concreto. La superestructura sería el engranaje de los AE y la infraestructura serían las formas en que se determinan, se imponen o se dan tales AE. 
amplio de prácticas que incluyen modos psicológicos de coerción, estructuras del lenguaje que proyectan una noción de sujeto enajenado y dispuesto para ejercer un papel decisivo en la producción de capital para las élites y el currículo de las instituciones educativas, diseñado generalmente para profundizar la brecha que hay entre las clases sociales, entre otros. En lo concerniente al aspecto educativo, Foucault (1972) señala en La arqueología del saber que la escuela pública emerge como un agente de movilización social frente a la consecución de diferentes discursos. Sin embargo, la preocupación del autor radica en la distribución de los mismos sin que haya una mediación del conflicto social:

La educación puede bien ser, por derecho, el instrumento por el que todo individuo, en una sociedad como la nuestra, puede ganar acceso a cualquier discurso. Pero bien sabemos que en su distribución, en lo que permite y en lo que evita, sigue la tan trillada línea de batalla del conflicto social. Cada sistema educativo es un medio político para mantener o modificar la apropiación de un discurso. (Foucault, 1972, p. 323)

Ante lo anterior, Foucault propone que esta relación de fuerza no es la violencia, sino que está mediada por una tensión constante entre mantener el sistema y el discurso 0 modificarlo; en este caso, la relación de fuerza forma parte siempre de una multiplicidad (Deleuze, 2014). El concepto de multiplicidad en Foucault (2002a) implica que el poder está articulado con la relación de fuerza y la fuerza; entre ambas nociones existe una distinción clave en la comprensión de la multiplicidad.

La fuerza es un ejercicio del poder, individual o colectivo, hacia otros individuos o grupos. La relación de fuerzas tiene que ver con las tensiones que se dan entre las fuerzas. Por consiguiente, esta noción no depende de un solo ente, de una sola institución o de un sujeto: son muchos seres, muchos objetos, muchas situaciones (multiplicidad); los individuos que viven la relación de fuerzas están inmersos en constantes tensiones. De modo que la violencia sería otra cosa: la relación de fuerza con un ser o un objeto [...], cuando sufro una violencia, no es mi fuerza la que sufre, es mi cuerpo, que quizá es la sede de una fuerza, la mía (Deleuze, 2014).

Se puede deducir que sucede lo mismo con la ideología, pues sería una relación de fuerza con el espíritu o la mente de un individuo: los sujetos no pueden escapar jamás de una ideología, pero no por ello significa que no estén expuestos a la aplicación de un régimen de fuerzas. Es decir, los individuos están expuestos a ser destruidos por una modalidad de represión o de ideología. Entonces, tanto la violencia como la ideología pueden demoler cuerpos y almas y, por consiguiente, existiría una relación de fuerzas con los objetos o los seres. 
Sin embargo, otra fuerza no es destruida por la fuerza (Deleuze, 2014). Es decir, la mayor exposición de los individuos no está en esas modalidades (violentas o represivas), sino en las modalidades de la sutileza. En esta perspectiva, la teoría foucaultiana abre un panorama que establece otro tipo de modalidades para el ejercicio del poder y sus procedimientos. Sobre todo en Vigilar y castigar, se incluyen las funciones del poder en los escenarios en donde se revela. Una de ellas, en la que el papel del poder toma bastante importancia, es definitivamente, la educación. Sin duda, a través de la modelación, del perfilamiento y de determinados saberes, los individuos entran en el régimen del poder y aceptan sus modalidades y sus mecanismos.

En ese sentido, las relaciones de fuerzas no serían en absoluto del tipo "hacer violencia" o "reprimir", sino del tipo "incitar, suscitar, combinar" (Deleuze, 2014). En los recientes estudios del poder y la comunicación (Cortés \& Isaza, 2017, Bauman, 2005), la manipulación de los medios de comunicación, las paparruchas, las fake news (noticias falsas en internet), se pueden asumir como relaciones de fuerzas. Es decir, una fuerza incita a otra, puede combinarse con otras (Deleuze, 2014), para desarrollar el ejercicio del poder mediante las modalidades de la sutileza. Esas sí son relaciones de fuerza (Deleuze 2014). Un ejemplo de ello son los comicios electorales entre Hillary Clinton y Donald Trump en los Estados Unidos, en noviembre de 2016. Una de las razones del triunfo puede tener origen en el manejo poco ortodoxo y objetivo de las redes sociales. Esta superioridad pudo haberse fomentado de forma artificial por el equipo de Trump al crear informáticamente miles de bots o cuentas ficticias desde las que amplificar sus mensajes en Twitter, dominar la conversación y generar trending topics (Rodríguez-Andrés, 2017).

Esta explicación es relevante a la hora de observar la operatividad del poder en las instituciones. Según Deleuze (2014), las relaciones de fuerzas que estudia Foucault en Vigilar y castigar serían tres: repartir en el espacio, ordenar en el tiempo y componer en el espacio-tiempo. Repartir en el espacio tiene que ver con "poner en fila en la escuela", encerrar, cuadricular, seriar (Deleuze, 2014). Ordenar en el tiempo tiene que ver con la fragmentación de las horas, de los minutos, de las medidas del tiempo. Para Deleuze (2014), esto significa subdividir el propio tiempo [...], programar un acto, descomponer un gesto. Finalmente, componer en el espacio-tiempo es producir un efecto "útil", superior a la suma de las fuerzas, a la suma de las fuerzas componentes.

Deleuze (2014) y, anteriormente, Foucault (2002a, 2002b) afirman que estas relaciones se pueden dar en distintos lugares como los talleres, las primeras fábricas, las cárceles y los hospitales psiquiátricos. En estos escenarios, la disposición arquitectónica es cuadriculada; tiene lugares específicos en los cuales se desarrollan funciones de vigi- 
lancia y de control, de realización de determinadas actividades y de mediación para obtener alimentos o elementos de dotación. Asimismo, se puede decir que estas relaciones de fuerza tienen similitud en el escenario de la escuela. Ejemplos tales como las filas de estudiantes, el restaurante escolar, las coordinaciones, las cámaras o los profesores de disciplina, la organización de los escritorios y pupitres en el salón de clases y las puertas, son una radiografía pertinente de la repartición en el espacio dentro de la escuela.

Asimismo, la asignación académica, la subdivisión de las horas y los bloques del horario, los tiempos de descanso, de clase y de tiempo libre, en la escuela, son una muestra fehaciente del ordenamiento en el tiempo que propone Foucault (2002a). De la misma forma, la imposición de hacer silencio, para producir ciertas posturas al estar en pie o sentado o las mecánicas del movimiento (acción-reacción en los cuerpos) constituyen ejemplos de la programación y el ordenamiento del cuerpo. En se sentido se puede decir:

La descomposición de los gestos, el trabajo mecánico son una función de ordenamiento del tiempo. Hay quizás una violencia subyacente intensa, pero no hay latigazos, no se ha formado a los obreros a latigazos [...] En un sentido fue peor que eso. (Deleuze, 2014, p.50)

Lo anterior comprende una similitud entre diferentes ámbitos, como son la escuela y la fábrica, en relación con el ordenamiento del tiempo, la repartición en el espacio y la composición en el espacio. Es decir, las sociedades no proceden por represión e ideología, sino por normalización [...] Normalizar es la relación de fuerzas por excelencia. A saber, es repartir en el espacio, ordenar en el tiempo, componer en el espacio, componer en el espacio-tiempo (Deleuze, 2014).

El concepto de normalizar termina siendo definitivo en la comprensión de la relación de fuerzas y del poder, como práctica y ejercicio en las esferas sociales y en diferentes instituciones, de las que se ha venido hablando. De modo que se puede deducir que el poder deviene normalización, si se tiene en cuenta que Foucault (2002a), en Vigilar y castigar, piensa que las instituciones tales como el hospital psiquiátrico y la cárcel están diseñadas para sujetos que están fuera de la normalidad. Si se observa con atención la anterior premisa, se está mostrando que las escuelas y las fábricas que guardan bastante afinidad arquitectónica y de organización de los espacios y los tiempos, tanto en los hospitales psiquiátricos como en las cárceles, tienen la función de ver el poder como un ejercicio de normalización.

Finalmente, el postulado de la legalidad representa un análisis sugestivo que se da entre legalidad e ilegalidad, entre ciertas posturas teóricas del poder, tanto las burguesas 
como las marxistas. En principio, la denuncia de Foucault (2002a) tiene que ver con seis de los postulados principales de tales teorías; Deleuze (2014) hace énfasis en que estas perspectivas se sustentan en un espacio macrofísico.

Para el caso de este sexto postulado, es crucial comprender el poder desde una dimensión microfísica. Si se entiende que las teorías clásicas del poder han visto sus diferentes dimensiones en torno de la oposición y de las grandes entidades (ámbito macrofísico), Foucault (2002a) propone pensar el poder desde una concepción molecular.

Precisamente $[\ldots]$ me interesa comentar la microfísica del poder. 0 si ustedes prefieren, digamos una concepción molecular del poder [...] Si uno se queda en las entidades molares, es obvio que piensa el poder en términos de oposición. Las grandes entidades se organizan según oposiciones molares [...] Es obvio que una microfísica del poder pretende traspasar las oposiciones molares. ¿Hacia qué? Hacia complementariedades molares [...] En otros términos, se trata de pasar de una dimensión macroscópica a una dimensión, en resumidas cuentas, microscópica. (Deleuze, 2014, p. 58-59)

Foucault (2002a) no miniaturiza el problema del poder en torno de una idea microscópica. Es preciso que haya verdaderamente diferencia de naturaleza entre el dominio macrofísico y el dominio microfísico (Deleuze, 2014). Primordialmente, la denuncia que estableció Foucault (2002a) a los postulados del poder provee elementos de discernimiento en torno a la comprensión molar del tiempo, del espacio y del espacio-tiempo dentro de ciertas instituciones. Esta denuncia exhibe el concepto de complementariedad y, para el caso del último postulado, que es el de la legalidad, tiene en cuenta la complementariedad entre ley e ilegalismo.

[...] En la mayoría de las teorías del poder, el poder es pensado en función de la ley, de la ley como instancia molar. Y desde entonces, la oposición molar correspondiente es ley/ilegalidad. Y que pensemos el poder a partir de la ley, es sin duda el signo de que la ley es una excelente noción molar para pensar el poder. (Deleuze, 2014, p.60)

Este giro es trascendente. No solo se trata de un cambio de vocablos, en este caso, ilegalismo por ilegalidad. Foucault (2002a) señala que en el nivel microfísico, la ley no se opone a la ilegalidad. Lejos de oponerse es una resultante de los ilegalismos. Los ilegalismos, entonces, vienen a ser una complementariedad de la ley, en la medida en que a través de la misma ley se legitiman situaciones, hechos y sucesos que no son legales. 
Esto es una forma de legitimar, de transformar lo ilegal en algo que es permitido por la misma ley o norma. Lo anterior demuestra que la ley no está especialmente hecha para prohibir (Deleuze, 2014). Está diseñada para discernir las formas en que se puede eludir. Por consiguiente, la ley se puede entender como una gestión de los ilegalismos en un campo social.

\section{Relación entre los postulados del poder y la educación co- lombiana}

En este apartado toma relevancia la teoría de Althusser $(1969,1971,1988)$ dentro del ámbito específico de la educación colombiana. Si bien la disertación de Foucault $(1988,2002 \mathrm{a}, 2002 \mathrm{~b})$ penetra hondamente en los escenarios de las escuelas, los talleres y los centros industriales y es en verdad acertada en un nivel epistemológico clave, también es importante recalcar que en la praxis, es decir, en las prácticas cotidianas y sociales de las diferentes instituciones, en Colombia, la teoría de Althusser $(1968,1971,1988)$ señala las dimensiones educativas propias del fenómeno de los sujetos que ejercen la dominación y aquellos que la sufren, de manera que reproducen la sociedad.

En el ámbito de la educación, la noción de ilegalismo toma fuerza desde premisas de carácter económico, social e, incluso, pedagógico. En ese sentido, no es en vano pensar que las teorías de la reproducción social ${ }^{9}$, desde diferentes sesgos y perspectivas, señalen que principalmente la educación y, por ende, las instituciones escolares inciden muy poco para el desarrollo individual, la movilidad social y el poder político y económico para los desposeídos y en desventaja (Giroux, 1983). En Colombia, la escuela tiene como función reproducir formas de exclusión y promover la proliferación del orden estatuido de la ideología dominante, con el objeto de perpetuar, por un lado, el estatuto del poder y, por otro, la seguridad de ejercerlo en los sujetos, sobre todo en el ámbito de la producción y del ejercicio laboral, como se verá en los siguientes párrafos.

La legitimación de ciertas prácticas del poder se da en diferentes esferas de la sociedad, tales como los medios masivos de comunicación, la iglesia, la religión, educación, normatividad, entre otras ${ }^{10}$. Primordialmente, la educación cumple un papel vital en la configuración de un escenario de aprendizaje para sitiar el ejercicio del poder en las es-

9 Estas teorías toman como referencia el hecho de que las sociedades se reproducen constantemente, a partir de los aparatos ideológicos del Estado o de los dispositivos pedagógicos o de las formas primigenias de la conservación cultural. La transformación de la sociedad en estas teorías es poco probable y la ubica en esferas como la imposibilidad, la desesperanza y la utopía.

10 Esta legitimación se ejemplificó con rigor en los primeros acápites especialmente, con las redes sociales, la escuela, la normativa y otros espacios de la vida social. 
cuelas. Las teorías de la reproducción toman como problema básico la noción de que las instituciones escolares ocupan un papel central, si no crítico, en la reproducción de las formaciones sociales necesarias para sostener las relaciones capitalistas de producción (Giroux, 2014).

En Colombia, uno de los énfasis primordiales en la articulación de la escuela pública con el Servicio Nacional de Aprendizaje (SENA), con el sector productivo y con las mismas universidades, se da desde un sesgo comercial o de emprenderismo ${ }^{11}$. La racionalidad de la articulación del SENA con la educación media tiene como consecuencia la reducción de la media y la educación de los colegios a la formación laboral del SENA como si fuera el único propósito educativo (Celis, Gómez \& Díaz, 2006). Por ello, se puede afirmar que las escuelas surgieron históricamente como sitios sociales que han integrado las tareas tradicionalmente separadas de reproducir habilidades de trabajo y de producir actitudes que legitimen las relaciones sociales en las que estas habilidades están localizadas (Giroux, 2014). En otras palabras, históricamente, los trabajadores se han entrenado siguiendo programas de aprendizaje para lograr adquirir las habilidades de trabajo necesarias para sus empleos (Aronowitz, 1973). Otro hecho clave, siguiendo la línea de disertación de Celis et al. (2006), es que la media en Colombia, desde un énfasis técnico-comercial o financiero, bajo esta dirección relacionan estas dos labores: la instrucción y la fuerza laboral. A pesar de no ser las únicas instituciones que las llevan a cabo, son las que más incidencia tienen en la división del trabajo, desde una visión deshumanizada que observa a los sujetos como mano de obra calificada.

La escolarización en Colombia personifica un espacio común que construye identidades, donde los estudiantes de diversas clases sociales asimilan capacidades necesarias para habitar el lugar particular en la ocupación del trabajo. Respecto a lo anterior, se puede hablar de las categorías del poder en el ejercicio escolar: imponer una tarea cualquiera a una multiplicidad cualquiera, a condición de que sea poco numerosa y administrar la vida en relación con otra multiplicidad (Deleuze, 2014).

11 El grupo de Articulación del SENA con el Sistema Educativo se enmarca dentro de las políticas y objetivos del Sistema Nacional de Formación para el Trabajo, definido como la estructura que deberá articular la oferta de formación para el trabajo, conformada por gremios, empresas, organizaciones de trabajadores, entidades de formación para el trabajo o de educación no formal, cajas de compensación familiar, entidades de educación media, técnica profesional, tecnológica, universidades y entidades gubernamentales, con el fin de definir e implementar políticas y estrategias para el desarrollo y calificación de los recursos humanos del país. Para esto se han creado diferentes programas e iniciativas: a) Programa de articulación con la media; b) Alianzas con Instituciones de Educación Superior; c) Programa de Ampliación de cobertura; d) Programa Jóvenes en Acción. e) Redes de entidades de formación para el trabajo. (SENA, s.f.). 
Estos son los dos aspectos del poder disciplinario; en otras palabras, estos imponen una tarea a una determinada masa escolarizada, en medio de un proceso administrativo de la disciplina, lo que, a su vez, enmarca la constitución ideológica de la condición de dominación y sumisión. Por consiguiente, los individuos no solo "viven" dentro de la ideología por medio de las prácticas de las que ellos participan en los aparatos ideológicos, sino que también están constituidos por ideología (Althusser, 1969, 1988), en este caso, la ideología de la dominación.

\section{Conclusiones}

Las teorías de Althusser $(1969,1971,1988)$ explican en la práctica el ejercicio de la dominación, como base de la cotidianidad de los escenarios de la educación colombiana. Sin embargo, las teorías de Foucault $(1988,2002 a, 2002 b)$ ofrecen un panorama alternativo, de frente a la posibilidad de transformar la esfera educativa con fundamento en procesos de racionalización del ejercicio del poder y las formas de acción y transformación humana.

Las instituciones educativas en Colombia ofician como mediadoras para efectuar un ejercicio instruccional que provee a los sujetos de herramientas básicas para el aprendizaje instrumental de trabajos que hagan parte integral de la vida laboral, como en el caso del SENA y de otras mediaciones de la Educación Técnica. Lo anterior puede asegurar la continuidad y el establecimiento del poder sobre los sujetos. En otras palabras, los discursos tradicionales del poder en las escuelas han encontrado un ritmo cíclico, dinámico y renovador para conservar sus sistemas de alienación y enajenación humana.

Pese a los incalculables problemas de nuestra cultura, se trata de una que se enmarca en el lenguaje como un medio instrumental de los discursos que circulan en ella (Foucault, 1988); como se mencionó en anteriores acápites, el hecho de que existan discursos en circulación, implica que la participación humana pueda ser capaz de alterar, modificar y transformar los alcances de distintos dispositivos de poder. Ejemplos históricos, tales como el derecho al voto para la mujer, los movimientos estudiantiles, el movimiento pedagógico, en Colombia, se convierten en una muestra clara de que los ejercicios de emancipación, en torno a las dinámicas y relaciones de poder, clarifican el panorama para una mayor participación humana.

Estas relaciones están ancladas en elementos teóricos, consecuentes con unas prácticas sociales de la actualidad, en los que toman forma los modos del ejercicio del poder, la ideología y el lenguaje. Sin embargo, no se puede escindir el proceso de pensamiento, reflexión y ejercicio crítico de la emancipación y la participación humana. A la 
par que se desbordan ejercicios de dominación, sobre todo teniendo en cuenta el avasallante proceso de globalización de la comunicación y de la modernidad líquida (Bauman, 2005), no es posible cercenar la esperanza de los individuos y sus posibilidades de acción. Es importante mantener esta comprensión de la cualidad transformadora y activa de la ideología cuando consideramos el vínculo entre ideología y participación humana (Giroux, 2014).

En síntesis, en esta disertación se señala que el poder incide de diversas maneras en el ámbito educativo. Por una parte, impregna las prácticas de la escolaridad a través de una estructura sistémica basada en la normativa y en un ejercicio recurrente que tiende a destruir cualquier intento de emancipación humana. Por otra parte, se apoya en aparatos del Estado que propenden a la preservación de este sistema, tales como los medios de comunicación, la iglesia y el Estado, entre otros. Sin embargo, como se ha venido señalando, el poder desde los postulados de Foucault (2002a), Deleuze (2014) y Giroux (2014), entre otros, no pertenece solamente a las élites, sino que brinda la oportunidad de ejercer una autonomía relativa de la escuela y la transformación de la cultura, por medio de procesos de pedagogía, lucha, resistencia y contrahegemonía.

\section{Referencias}

Althusser, L. (1969). La revolución teórica de Marx. México: Siglo XXI.

Althusser, L. (1971). Ideología y los aparatos ideológicos de Estado. B. Brewster (trad.). Nueva York: Monthly Review Press.

Althusser, L. (1988). Para leer "El Capital". México: Siglo XXI.

Aronowitz, S. (1973). Falsas promesas. Nueva York: Mc Graw Hill.

Bauman, Z. (2005). Los retos de la educación en la modernidad líquida. Barcelona: Gedisa.

Celis, J.E., Gómez, V. M. \& Díaz, M. (2006). ¿Educación media o articulación con el SENA? Un análisis crítico al programa de articulación en Bogotá. Bogotá: Instituto de Investigación en Educación, Universidad Nacional de Colombia.

Cortés, C. \& Isaza, L. (2017). Noticias falsas en Internet: la estrategia para combatir la desinformación. Buenos Aires: Centro de Estudios en Libertad de Expresión y Acceso a la Información (CELE), Universidad de Palermo.

Deleuze, G. (2014). El poder: curso sobre Foucault II. Buenos Aires: Cactus.

Foucault, M. (1988, jul.-sep.). El sujeto y el poder. Revista Mexicana de Sociología, 50(3), 3-20. 
Foucault, M. (2002a). La arqueología del saber. A. Garzón del Camino (trad.). Buenos Aires: Siglo XXI.

Foucault, M. (2002b). Vigilar y castigar: nacimiento de la prisión. A. Garzón del Camino (trad.). Buenos Aires: Siglo XXI.

Gilabert, J. (2014). Bases para un debate sobre la Gioconda del Prado. Recuperado de http:// www.lacasadelarbol.es/3Gioconda.pdf

Giroux, H. (1983). Teorías de la reproducción y la resistencia en la nueva sociología de la educación: un análisis crítico. G. Morza (trad.). Buenos Aires: Harvard Education Review.

Giroux, H. (2014). Teoría y resistencia en educación. Una pedagogía para la oposición. A. T. Méndez (trad.). México: Siglo XXI.

Jäger, S. (2003). Discurso y conocimiento: aspectos teóricos y metodológicos de la crítica del discurso y del análisis de dispositivos. En R. Wodak \& M. Meyer (comp.), Métodos de análisis crítico del discurso (pp. 61-100). Barcelona: Gedisa.

Lapierre, J. W. (1959). El poder político. Paris: Gallimard.

Marx, K. \& Engels, F. (2000). El manifiesto comunista. Recuperado de https://sociologialunpsjb. files.wordpress.com/2008/03/marx-manifiesto-comunista.pdf

Meyer, M. (2003). Entre la teoría, el método y la política: la ubicación de los enfoques relacionados con el ACD. En R. Wodak \& M. Meyer (comp.), Métodos de análisis crítico del discurso (pp. 35-59). Barcelona: Gedisa.

Pérez, P. F. (2007). Dos extraños compañeros de cama. La ideología y el poder en Althusser y Foucault. Tábula Rasa, (7), 144-177.

Rodríguez-Andrés, R. (2018). Trump 2016: ¿presidente gracias a las redes sociales? Palabra Clave, 21(3), 831-859. D0I: 10.5294/pacla.2018.21.3.8

Servicio Nacional de Aprendizaje -SENA-. (s.f.). Articulación con el Sistema Educativo. Recuperado de http://www.sena.edu.co/es-co/formacion/Paginas/Articulaci\%C3\%B3ncon-el-Sistema-Educativo.aspx 


\section{PEDAGOGÍA DEL LENGUAJE PEDAGOGY OF LANGUAGE PÉDAGOGIE DU LANGUAGE PEDAGOGIA DA LINGUAGEM}

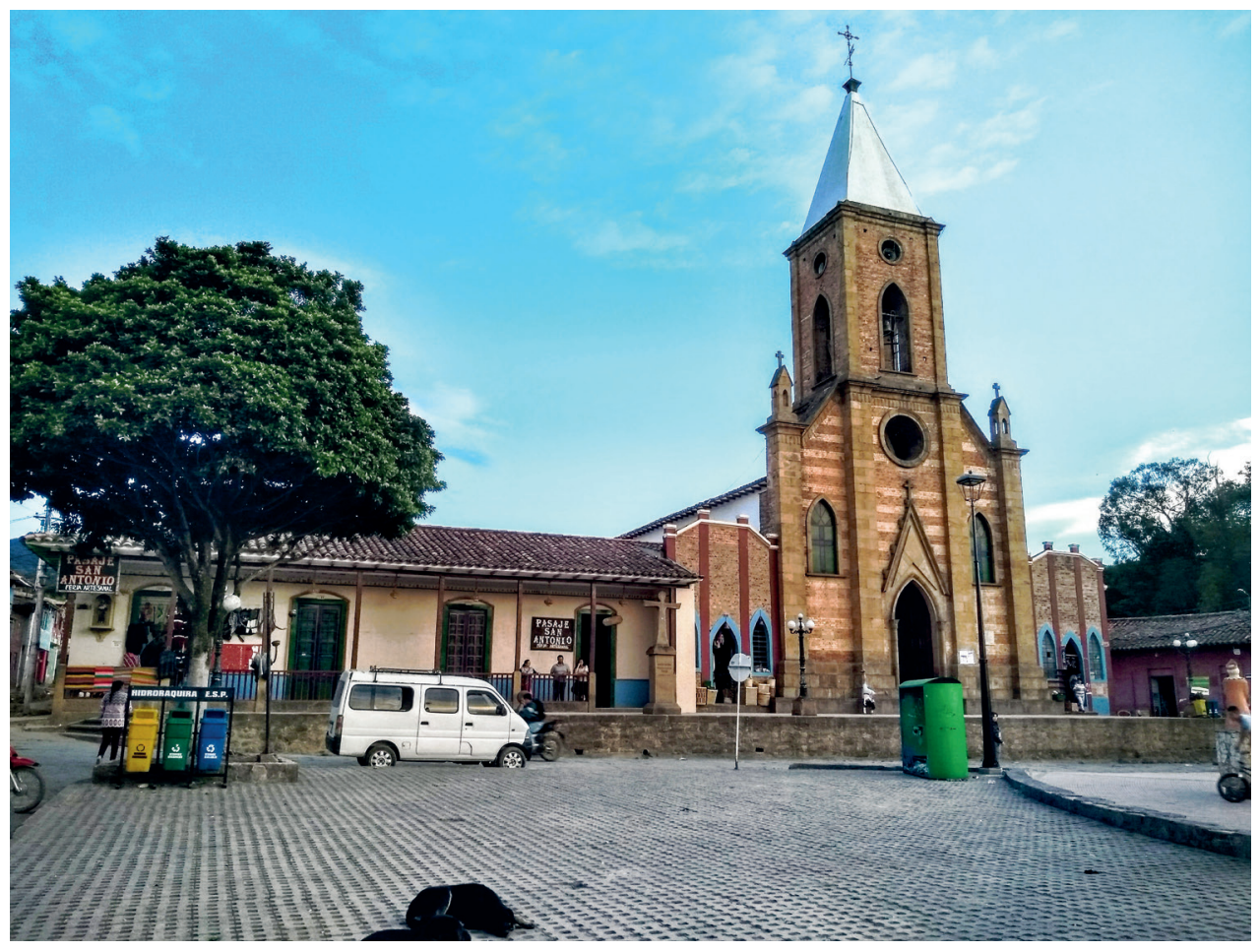

Ráouira

Pueblo anterior a la Conquista española y refundado en 1580 por Fr. Francisco de Orejuela, misionero de la Orden de San Agustín, fue lugar de paso de Gonzalo Jiménez de Quezada, el 11 de marzo de 1537. Así mismo, es cuna del compositor de música carranguera, Jorge Velosa. Este municipio, famoso por su arquitectura de tipo colonial con colores fuertes que realzan la alegría de sus habitantes, es considerado la capital artesanal de Colombia y galardonado por la Corporación Nacional de Turismo en 1994 como uno de los pueblos más bellos de Boyacá; De igual manera, se destaca por sus artesanías (cerámica, tejidos de sacos, canastos, vestidos, hamacas, etc.), las cuales son reconocidas en Colombia y en el extranjero. 
